\title{
I mplementing the Agenda for Global Action on human resources for health: analysis from an international tracking survey
}

\author{
Sophie Witter ${ }^{1}$, Giorgio Cometto ${ }^{2}$, Rashid Uz Zaman ${ }^{1}$, Mubashar Sheikh², Suwit Wibulpolprasert ${ }^{3}$ \\ 1. Health Portfolio, Oxford Policy Management (OPM), Oxford, United Kingdom. 2. Global Health Workforce Alliance \\ (Alliance), World Health Organization, Geneva, Switzerland. 3. Senior Advisor on Disease Control, Ministry of Public \\ Health, Thailand and Chair, Technical working group for Monitoring and Evaluation, Kampala Declaration/Agenda for \\ Global Action, Thailand.
}

Correspondence: Giorgio Cometto. Address: Global Health Workforce Alliance (Alliance), World Health Organization, Avenue Appia 20, CH-1211 Geneva 27, Switzerland. E-mail: giorgiocometto@hotmail.com

Received: October 11,2012

DOI : $10.5430 /$ jha.v2n1p77
Accepted: October 30, 2012

URL: http://dx.doi.org/10.5430/jha.v2n1p77

\section{Abstract}

Objective: A survey was conducted to analyse the governance and policy environment for human resources for health (HRH) development in 57 priority countries, with the objective of understanding the linkages between policy and context factors.

Methods: Responses to a questionnaire tracking proxy indicators were received from 51 (89\%) countries. Findings are presented by frequency; correlations were investigated through cross tabulations and multiple regression analysis.

Results: The results indicate uneven performance among countries and across different domains of health workforce development. The only indicator showing a significant correlation with other areas of performance was implementing an HRH plan. No significant correlation with contextual factors was found.

Discussion: Progress in addressing HRH challenges appears to be independent of contextual factors, suggesting that countries can improve their performance through concerted action by stakeholders. Having and implementing an HRH plan appears to be a key factor in galvanising that action.

\section{Key words}

Health manpower, Developing countries, Review, Progress report

\section{I ntroduction}

It has long been recognized that the persistent shortage of health workers is a major obstacle to achieving the health Millennium Development Goals (MDGs) ${ }^{[1-3]}$, a fact recently reiterated also by the United Nations Global Strategy for Women's and Children's Health ${ }^{[4]}$.

Building on the pioneering work on human resources for health of the Joint Learning Initiative ${ }^{[5]}$, the World Health Report 2006 identified 57 priority countries which fell below the threshold of 2.3 physicians, nurses and midwives for every 1,000 people - the minimum number considered generally necessary to deliver essential health services ${ }^{[6]}$. 
In Africa, low-income countries with critical shortages in health workforce are Benin, Burkina Faso, Burundi, Central African Republic, Chad, Comoros, Democratic Republic of Congo, Equatorial Guinea, Eritrea, Ethiopia, Gambia, Ghana, Guinea, Guinea-Bissau, Kenya, Liberia, Madagascar, Malawi Mali, Mauritania, Mozambique, Niger, Rwanda, Sierra Leone, Somalia, Togo, Uganda, United Republic of Tanzania, Zambia, and Zimbabwe. Lower-middle income countries, instead, include Angola, Cameroon, Congo, Côte d'Ivoire, Djibouti, Lesotho, Morocco, Nigeria, and Senegal.

In Asia, six low-income countries (Afghanistan, Bangladesh, Cambodia, Lao People’s Democratic Republic, Myanmar, and Nepal) and six lower-middle income countries (Bhutan, India, Indonesia, Iraq, Pakistan, and Yemen) are experiencing severe shortages of health workers.

In Central America, Haiti, a low-income country, alongside El Salvador, Honduras, and Nicaragua, three lower-middle-

income countries, are lacking sufficient numbers of health professionals.

In South America, only Peru, an upper-middle income country, is facing shortages of skilled health staff.

In Australasia, Papua New Guinea, a lower-middle income economy, is the sole country without an adequate health workforce.

Other related HRH challenges include maldistribution, the external brain-drain, the inadequate working environment, the inadequate motivation and incentives, and the sometimes weak management and support provided by health systems.

Table 1. Agenda for global action (AGA) and its progress indicators

\begin{tabular}{ll}
\hline AGA strategies & Progress indicators \\
\hline $\begin{array}{l}\text { Building coherent national and global leadership } \\
\text { for health workforce solutions }\end{array}$ & $\begin{array}{l}\text { Number of countries that have developed costed and evidence-based HRH plans. } \\
\text { Number of countries with an inter-sectoral coordination mechanism for involving } \\
\text { relevant stakeholders in HRH development } \\
\text { Number of countries with a national mechanism (e.g. HRH observatory) with } \\
\text { pnsuring capacity for an informed response }\end{array}$ \\
$\begin{array}{l}\text { based on evidence and joint learning } \\
\text { making and management of the health workforce }\end{array}$ \\
$\begin{array}{l}\text { Number of countries which have a well-functioning HRH information system } \\
\text { Retaining an effective, responsive and equitably }\end{array}$ \\
$\begin{array}{l}\text { Number of countries having implemented programs to increase the production of } \\
\text { distributed health workforce } \\
\text { Managing the pressures of the international } \\
\text { health workforce market and its impact on } \\
\text { migration }\end{array}$ & $\begin{array}{l}\text { Number of countries implementing strategies/approaches for attracting and } \\
\text { retaining the health workforce in underserved areas }\end{array}$ \\
$\begin{array}{l}\text { Securing additional and more productive } \\
\text { investment in the health workforce }\end{array}$ & $\begin{array}{l}\text { Number of countries in which budgetary allocations for health workers as a } \\
\text { proportion of the health sector budget has increased } \\
\text { Number of countries that have received additional investment from multilateral and } \\
\text { bilateral partners for the implementation of HRH plans }\end{array}$ \\
\hline
\end{tabular}

The first Global Forum on Human Resources for Health in 2008 held in Kampala, Uganda, resulted in the adoption of the Kampala Declaration and Agenda for Global Action (KD/AGA), which became the overarching framework to address the health workforce crisis for stakeholders at country, regional and global levels ${ }^{[7]}$.

The Global Health Workforce Alliance (the "Alliance") was given the mandate to monitor, document and share progress. In the run-up to the second Global Forum for HRH in Bangkok in January 2011, a survey was conducted to assess the 
human resources for health (HRH) governance and policy environment in the 57 priority countries, representing the first attempt to systematically track the implementation of the KD/AGA ${ }^{[8]}$.

This article presents an in-depth statistical and econometric analysis of the survey data, investigating the existence of significant relationships between different national HRH policy, governance and context factors. Although general policy directions to support health workforce development have been identified through the KD/AGA, there is a dearth of evidence on which targets are being met and the relative importance of different strategies. This analysis was undertaken to explore these issues, and its findings can be used to strengthen the health policy and governance environment in which HRH development takes place.

\section{Methods}

The Alliance convened a Technical Working Group comprising international experts in HRH to oversee and provide technical assistance to the KD/AGA monitoring. Given that there were no agreed indicators to monitor the KD/AGA ${ }^{[9]}$, the TWG developed a set of proxy indicators for tracking each of the KD/ AGA strategies (see Table 1). As the data collection was to take place little over two years after the KD/AGA launch, it was decided to focus primarily on input and process indicators (existence of supportive policies and strategies, governance structures, investment decisions), considering that changes in output indicators (such as health workforce availability and distribution) take a longer time to demonstrate measurable changes.

A structured questionnaire (in English, French, Spanish and Portuguese) with 47 questions covering nine progress indicators was sent in July 2010 to Ministries of Health in the 57 priority countries (the questionnaire is available as web appendix 1). The respondents to the questionnaire were the officials in charge of human resources for health in Ministries of Health (Directors of Human Resources for Health, or equivalent job title).

By October 2010, completed questionnaires were received from 51 countries (89\% response rate). Consistency checks were run in order to identify internal inconsistencies between responses. For example if a country reported not to have a HRH plan, but subsequently reported to have implementing the HRH plan, then enquiries were made to establish which response was correct. Where outliers were identified, these were checked against additional sources to ensure their accuracy. The findings were presented through a KD/ AGA progress report ${ }^{[8]}$ at the Second Global Forum on Human Resources for Health, held in Bangkok, Thailand, which was attended by delegates from each of the responding countries, and provided a venue for the validation of responses to the questionnaire. The findings of the report were presented in a plenary session and discussed further in several other sessions. Feed-back and comments on the report were explicitly encouraged. Over one year after its launch, no errors and inconsistencies were noted, and no correction was requested by the countries or other stakeholders.

The survey data were tabulated and analysed with STATA (the complete dataset is available as web appendix 2). Secondary data on the countries' HRH availability and contextual factors were obtained from WHO's Global Atlas of the Health Workforce (http://apps.who.int/globalatlas/) and the World Bank database (http://data.worldbank.org/).

A quantifiable scoring method was adopted to measure the progress of each country in a single index. There were 43 dichotomous variables and the 'yes' responses were given ' 1 ' and 'no' or blank fields were given ' 0 ' points. In the 4 ordinal variables (exploring, for instance, frequency of updating of health workforce statistics) points were allocated as 0 , 0.5 and 1. Individual indicators were scored and the results were expressed in percentages. For example if there were 5 variables included for one indicator, and a country had 3 'yes' responses, then $60 \%$ was the final score. This implies equal weight across each variable. 
The detailed findings of the survey are presented elsewhere ${ }^{[8]}$. In this article only a concise overview of the descriptive findings is provided as essential background information, while the main focus of this analysis is to investigate the existence of correlations between variables within the country dataset, and between variables and contextual factors. To observe the association between the dependent and independent variables and to calculate the odds ratio and level of significance, logistic regression was carried out. If the number of observation was 0 in any strata, then exact logistic regression was performed.

Limitations and constraints of the study should be highlighted to better contextualise and interpret its findings: the absence of baseline data prevented any trend analysis; the self-reported nature of the responses made them prone to a certain level of subjectivity; and the focus on process issues and binary (yes/no) questions, which have limitations in terms of content., precluded for instance an analysis of the quality and comprehensive nature of HRH plans, the functionality of relevant governance structures and coordination mechanisms, or the quantification of additional investments. Some of the questions were hard for respondents to answer and therefore have fairly high non-response rates: for example $27 \%$ of respondents were unable to answer the question on staffing in private hospitals, highlighting as an additional limitation that the responses may suffer from a bias towards policies and processes in the public sector, even though the majority of the questions were framed in comprehensive terms that should span both the public and private health workforce.

Another important constraint to be noted is the paucity and incompleteness of comparable and updated HRH data in secondary datasets, which limited our ability to explore links between HRH processes with HRH output data (availability, distribution, etc.).

Finally, we note that the analysis of correlations between the indicators was limited by the sample size and by the fact that, for some indicators, the majority of respondents fall into one category. The absence of some of the anticipated statistically significant correlations therefore does not rule out the existence of such relationships.

\section{Results}

\subsection{Performance across areas of the Agenda for Global Action (AGA)}

For AGA 1 ('Building coherent national and global leadership for health workforce solutions'), most priority countries (44 out of 51 respondents; 86\%) reported having HRH plans, although there was slower progress in developing accompanying cost estimates and budgets (25; 49\%). Implementation was also lagging behind planning (24; 41\%).

Two-thirds of respondent countries (33; 65\%) had a national coordinating committee for $\mathrm{HRH}$, with a varying degree of outside representation: other ministries (education, finance, labour, etc) were represented in 28 countries (55\%), non-government organisations in 24 (47\%), external partners in 29 (57\%).

In relation to AGA 2 ('Ensuring capacity for an informed response based on evidence and joint learning'), fewer than half the reporting countries (22; 43\%) had mechanisms, such as HRH observatories), to share data and learning on HRH issues. Most countries reported good availability of HRH statistics for higher level cadres, but less so for community health workers (CHWs). Around half of the countries had updated statistics once or twice in the past two years. Data were mostly available on employment categories (41, or $80 \%$ ) and distribution (44, or $86 \%$ ), but not to track international migration (10, or $20 \%)$.

In relation to AGA 3 ('Scaling up health worker education and training'), most countries reported an increased enrolment for training for higher level cadres since 2008, especially for physicians and nurses (47, 92\%), and midwives (45, 88\%), less so for CHWs (31, 61\%). International scholarships increased in 32 countries (63\%); 32 countries (63\%) established new training institutes; and 35 (67\%) modified their training curricula in the last two years. 
In relation to AGA 4 ('Retaining an effective, responsive and equitably distributed health workforce'), 32 countries (63\%) reported having implemented strategies to retain workforce in under-served areas (e.g. better financial and non-financial incentives for rural posts, improved career development opportunities, etc.).

On AGA 5 ('Managing the pressures of the international health workforce market and its impact on migration'), just under two-thirds of countries (32; 63\%) had increased salaries, allowances or benefits for health workers to favour retention in the country. Most also reported improvements to career development for physicians, nurses and midwives. Corresponding improvements for CHWs occurred less than a third of countries (18, or 35\%), which is not a surprising finding considering that this last cadre is not prone to international migration.

For the final strategy, AGA 6 ('Securing additional and more productive investment in the health workforce'), increased recruitment - funded by either domestic or international sources - was reported in around $80 \%$ of countries for physicians, nurses and midwives, though the proportion was lower for CHWs (just over half). 39 countries (76\%) were receiving support from donors to implement some or all of their HRH plans.

The consolidated scores across the nine progress indicators, giving equal weight to all questions asked within each indicator, show that the highest performance was in relation to increasing production of HRH (AGA 3) and attracting support from development partners for HRH plans (AGA 6) - see figure 1 below.

The lowest scores related to the existence of mechanisms to inform policy-making through data sharing (AGA 2), the inclusiveness of HRH coordination mechanisms (AGA 1), and strategies to favour in-country retention (AGA 5). However, as there were no baseline data, conclusions cannot be drawn on trends.

Figure 1. Consolidated results across nine progress indicators

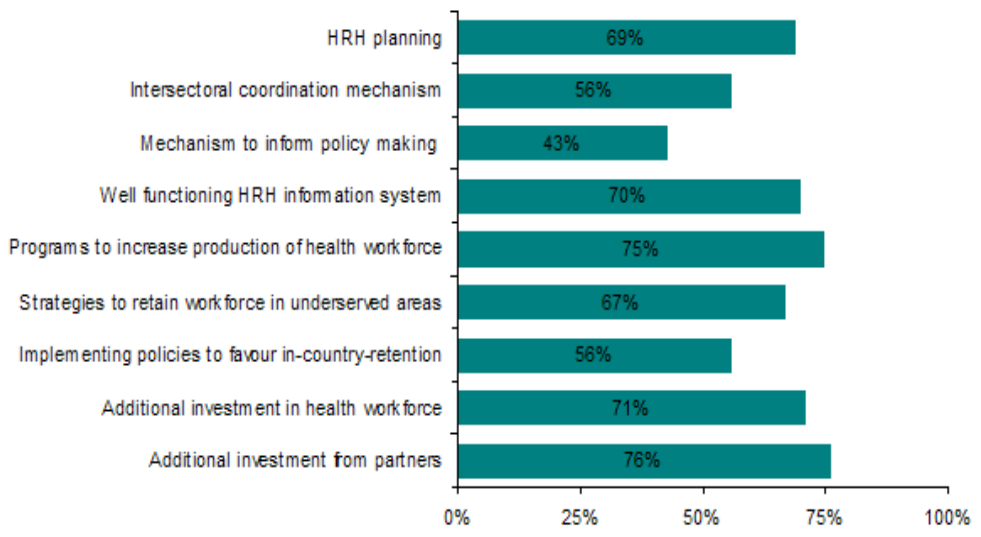

More detailed information on the performance of each country across all indicators is available in web appendix 2.

\subsection{I nter-relationships between indicators}

On the basis of the survey findings, we examined the correlation between different indicators in the survey data, but found few significant relationships.

The only correlation with clear statistical significance was between reported implementation of an HRH plan and good performance in the other indicators (see Table 2). 
Table 2. Effect of implementing national HRH plan on progress

\begin{tabular}{|c|c|c|c|c|}
\hline Progress & $\begin{array}{l}\text { Countries } \\
\text { implementing } \\
\text { HRH plan } \\
\mathrm{N}=29 \\
\mathrm{n}(\%)\end{array}$ & $\begin{array}{l}\text { Countries not } \\
\text { implementing } \\
\text { HRH plan } \\
\mathrm{N}=22 \\
\mathrm{n}(\%)\end{array}$ & Odds ratio & $\boldsymbol{P}$ \\
\hline Presence of a national committee* & $24(83)$ & $9(41)$ & 6.93 & 0.00 \\
\hline Non-MoH participation in national committee & $19(66)$ & $9(41)$ & 2.74 & 0.08 \\
\hline Non-public sector participation in national committee & $16(55)$ & $8(36)$ & 2.15 & 0.19 \\
\hline External partners in national committee* & $21(72)$ & $8(36)$ & 4.59 & 0.01 \\
\hline Presence of HRH observatory* & $16(55)$ & $6(27)$ & 3.28 & 0.05 \\
\hline HRH statistics exist for physicians & $29(100)$ & $20(91)$ & 3.29 & 0.36 \\
\hline HRH statistics exist for nurses & $29(100)$ & $21(95)$ & 1.31 & 0.86 \\
\hline HRH statistics exist for midwives & $28(97)$ & $20(91)$ & 2.80 & 0.41 \\
\hline HRH statistics exist for CHWs & $16(55)$ & $15(68)$ & 0.57 & 0.35 \\
\hline Regularly updated HRH statistics for physicians & $28(97)$ & $18(82)$ & 6.22 & 0.08 \\
\hline Regularly updated HRH statistics for nurses & $28(97)$ & $19(86)$ & 4.42 & 0.18 \\
\hline Regularly updated HRH statistics for midwives* & $28(97)$ & $17(77)$ & 8.24 & 0.03 \\
\hline Regularly updated HRH statistics for CHWs & $16(55)$ & $14(64)$ & 0.70 & 0.54 \\
\hline Statistics analyzed for employment status & $25(86)$ & $16(73)$ & 2.34 & 0.24 \\
\hline Statistics analyzed for geographical distribution & $27(93)$ & $17(77)$ & 3.97 & 0.12 \\
\hline Statistics analyzed for out-migration & $8(28)$ & $2(9)$ & 3.81 & 0.12 \\
\hline Increased training enrolment for physicians & $25(86)$ & $22(100)$ & 0.23 & 0.19 \\
\hline Increased training enrolment for nurses & $25(86)$ & $22(100)$ & 0.23 & 0.19 \\
\hline Increased training enrolment for midwives & $25(86)$ & $20(91)$ & 0.63 & 0.61 \\
\hline Increased training enrolment for CHWs & $15(52)$ & $16(73)$ & 0.40 & 0.13 \\
\hline Increase in international scholarships & $18(62)$ & $14(64)$ & 0.94 & 0.91 \\
\hline New medical or nursing schools & $17(59)$ & $15(68)$ & 0.66 & 0.49 \\
\hline Curriculums developed in response to health needs & $23(79)$ & $12(55)$ & 3.19 & 0.06 \\
\hline Strategies to retain workforce in underserved areas* & $22(76)$ & $10(45)$ & 3.77 & 0.03 \\
\hline More vacancies in public sectors for physicians & $23(79)$ & $19(86)$ & 0.61 & 0.52 \\
\hline More vacancies in public sectors for nurses & $20(69)$ & $19(86)$ & 0.35 & 0.16 \\
\hline More vacancies in public sectors for midwifes & $22(76)$ & $16(73)$ & 1.18 & 0.80 \\
\hline More vacancies in public sectors for CHWs & $17(59)$ & $14(64)$ & 0.81 & 0.72 \\
\hline Increase in private hospital staffing & $15(52)$ & $10(45)$ & 1.29 & 0.66 \\
\hline Increase in new facility in urban areas & $22(76)$ & $19(86)$ & 0.50 & 0.36 \\
\hline Increase in new facility in rural areas & $21(72)$ & $15(68)$ & 1.23 & 0.74 \\
\hline Incentives to work in remote areas* & $22(76)$ & $10(45)$ & 3.77 & 0.03 \\
\hline Career development for physicians* & $25(86)$ & $10(45)$ & 7.50 & 0.00 \\
\hline Career development for nurses* & $22(76)$ & $9(41)$ & 4.54 & 0.01 \\
\hline Career development for midwives* & $19(66)$ & $8(36)$ & 3.33 & 0.04 \\
\hline Career development for CHWs & $11(38)$ & $7(32)$ & 1.31 & 0.65 \\
\hline Increased recruitment in public sector for physicians & $25(86)$ & $16(73)$ & 2.34 & 0.24 \\
\hline Increased recruitment in public sector for nurses* & $27(93)$ & $15(68)$ & 6.30 & 0.03 \\
\hline Increased recruitment in public sector for midwifes & $25(86)$ & $14(64)$ & 3.57 & 0.07 \\
\hline Increased recruitment in public sector for CHWs & $14(48)$ & $13(59)$ & 0.65 & 0.44 \\
\hline Improvement in workplace environment & $22(76)$ & $11(50)$ & 3.14 & 0.06 \\
\hline Donor support for HRH development & $25(86)$ & $14(64)$ & 3.57 & 0.07 \\
\hline
\end{tabular}

* Statistically significant associations are highlighted in bold

Compared to countries which were not implementing an HRH plan, the odds of having a national coordination committee were seven times higher in countries implementing the plan. Similarly, the odds were eight times higher for having 
regularly updated statistics for midwives, four times higher for having strategies to retain staff in underserved areas, between three and seven times higher for having career development plans for midwives, nurses and doctors, and six times higher for having increased recruitment in the countries implementing HRH plan. The differences in percentage proportions for these attributes are also clearly evident (Figure 2).

Figure 2. Performance of countries with or without an implemented national HRH plan (indicators showing a significant difference)

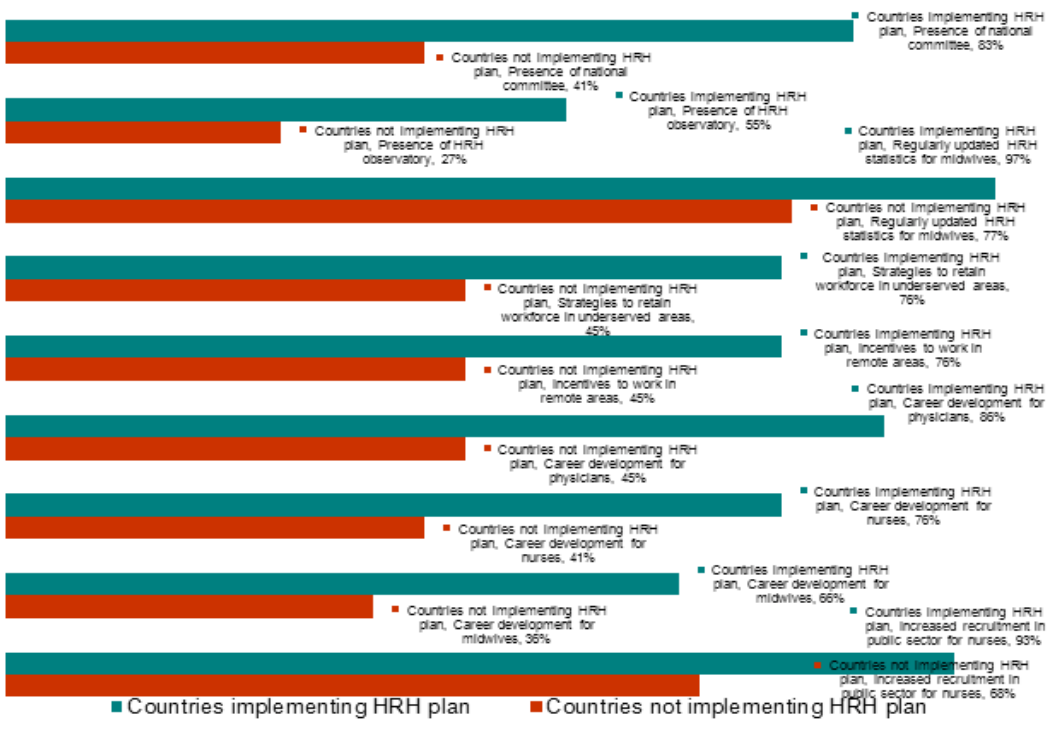

Many of the associations between existence of a national HRH plan and other indicators are positive, but not statistically significant because of small sample sizes. Importantly, all the significant associations with implementation of a national HRH plan are 'positive’ associations.

Even for variables where correlations were not statistically significant, there are descriptive findings of interest: for example 64\% (14 out of 22) of countries not implementing an HRH plan reported receiving donor support for their health workforce response, indicating the existence of significant project support from donors, unlinked to a national HRH strategy.

There are also some associations between individual indicators and the overall performance score of a country (e.g. countries having a national plan have significantly better overall scores). However, as the overall score is built on the basis of scores of individual indicators, these variables are not independent and therefore correlations are not reported here.

\subsection{Relationship with context variables}

We examined whether there were common features of countries which performed relatively well in relation to the AGA indicators and that could provide an explanatory model for the different performance of countries in tackling their health workforce challenges. We hypothesized that a range of socio-economic and health systems variables could potentially influence performance across areas of the AGA: gross national income, population size, per capita health expenditure, government expenditure as proportion of total health expenditure, expenditure on health as a proportion of total government expenditure, and density of physicians, nurses and midwives. Although the secondary data for these context variables were collected prior to the actions tracked in our questionnaire, they do not tend to change quickly.

We carried out simple linear regressions, using countries' total progress score as the dependent variable and the above independent variables, and no significant associations were found. 
This could be largely due to the small sample size; however, scatter plots (Figure 3) also reveal the lack of clear pattern between overall performance across the KD/AGA areas and the context variables which were expected, $a$ priori, to have a positive association with it.

Figure 3. KD/AGA progress scores plotted in relation to context variables

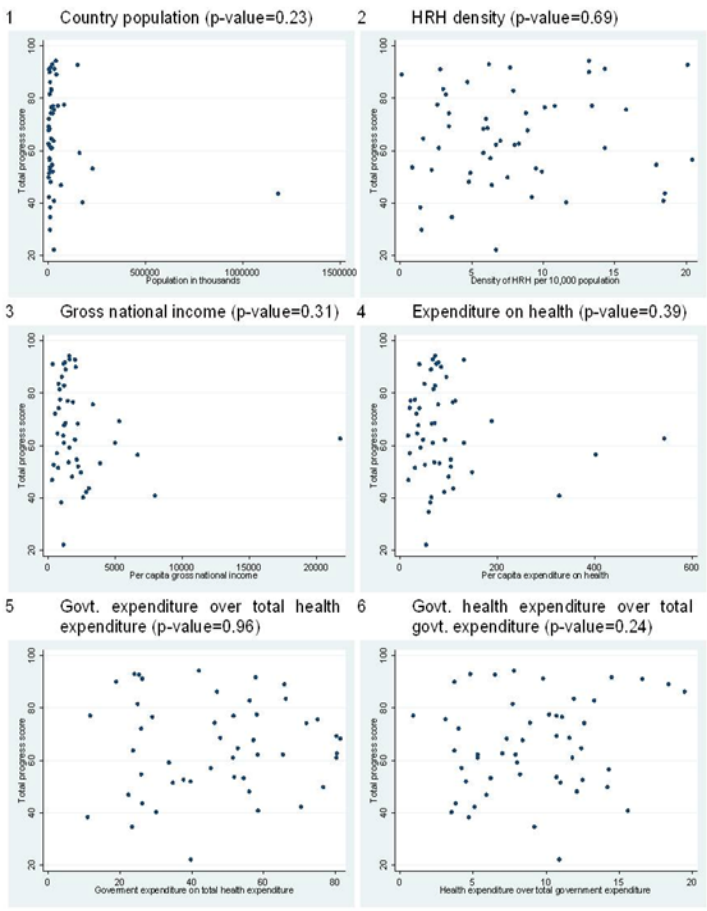

\section{Discussion}

Despite the limitations noted above, the survey provides a useful cross-sectional picture of the HRH policy and governance environment in the 57 priority countries, building on and complementing previous work to examine in more detail the content of HRH strategies, plans and policies ${ }^{[9]}$.

In terms of leadership (AGA 1), the reported data highlight the need to increase efforts towards the costing, funding and implementation of HRH strategies and plans, and to consistently ensure broader engagement of relevant stakeholders in the HRH development processes ${ }^{[10]}$.

With regard to evidence (AGA 2), the findings reiterate the need for stakeholders to work together to strengthen institutional capacity to regularly collect, analyze and especially share health workforce data, including through $\mathrm{HRH}$ observatories, to better inform managerial and policy decisions ${ }^{[11]}$.

The impact of the reported increases in enrolment in education (AGA 3) and training programmes could be maximized through a more efficient and sustainable skills mix, by awarding higher priority to non-traditional cadres such as community-based health workers (the survey revealed a lesser scale-up in training of these cadres compared to physicians, nurses and midwives) ${ }^{[12,13]}$.

In the critical area of retention (AGA 4), almost two thirds of countries reported efforts towards retaining health workers in underserved areas. It is however unclear what mix of policy options have been adopted, the extent to which these reflect best practice rooted in available evidence and normative guidance ${ }^{[14,15]}$, and whether they are having the desired effects. 
Efforts in improving domestic working conditions will undoubtedly contribute to addressing international migration (AGA 5) challenges, but their impact could be maximized if both source and destination countries cooperated to develop systems and processes for the effective implementation and monitoring ${ }^{[16]}$ of the WHO Global Code of Practice on International Recruitment of Health Personnel ${ }^{[17]}$.

The report findings hint to growing momentum for additional investments (AGA 6) in health workforce development. The extent and impact of such investments could be maximized by relaxing macroeconomic restrictions hindering a scale-up of domestic investment ${ }^{[18]}$, improving the effectiveness of spending ${ }^{[19]}$, and by ensuring that international support is fully additional ${ }^{[20]}$, predictable, long-term, aligned to country needs, and flexible, allowing for investment in both training and deployment of non-disease specific health personnel ${ }^{[21]}$.

The absence of significant findings from the multiple regression analysis on contextual factors is also revealing, in that it suggests that there is no clear relationship between context variables and overall performance on the HRH strategies. This indicates that countries with a challenging environment, including a limited resource base or a low baseline level of health worker availability, can still make progress through concerted action by all stakeholders. Having and implementing an HRH strategy or plan appears to be a key factor in catalysing such action.

The finding on the significant relationship between implementing an $\mathrm{HRH}$ plan and other positive performance indicators (such as having improved the workplace environment or having introduced incentives for health workers to stay in underserved areas), notwithstanding question marks on the direction of influence among these variables, reinforces the case for having and implementing strategies and plans for HRH development ${ }^{[22]}$. The association between having a national HRH coordination mechanism and implementing the HRH plan, furthermore, points to the need to create the necessary governance structures for collaboration among stakeholders.

This analysis provides new insights into the factors underpinning an effective response to health workforce challenges faced by countries, but at the same time clear gaps in evidence also emerged. Future similar analyses might strengthen further the evidence base for policy making and planning by investigating several related areas, including:

The quality of HRH plans and the factors that underpin their successful development and implementation; The determinants of functionality of national HRH coordination mechanisms; The competency frameworks and training curricula that enable an optimal skills mix; and Trends in health expenditure for $\mathrm{HRH}$, from both domestic and international resources.

Similar monitoring efforts should be undertaken on a regular basis (e.g. at 2-3 years intervals). The focus, however, should progressively broaden from input and process indicators (e.g. the existence of strategies, plans and policies) to output indicators (e.g. the availability and distribution of health personnel). Individual countries should set up or strengthen, as relevant to the local context, their own monitoring and tracking mechanisms to assess progress at local and national levels, and create the necessary linkages with policy-making and planning processes.

Despite the persistent evidence gaps, a clear picture emerged from the survey, showing uneven progress in different domains of health workforce development and across countries. This calls for renewed efforts by countries to accelerate implementation of the KD/AGA ${ }^{[23]}$, a message that was clearly reiterated also at the Second Global Forum on Human Resources for Health in January $2011^{[24]}$. 


\section{Acknowledgments}

This article is based on a study conducted by the Global Health Workforce Alliance (Alliance) and Oxford Policy Management (OPM). The collection of relevant data was made possible through the patient collaboration of staff of ministries of health from the priority countries who responded to the questionnaire. Alison Osborne and Waranya Teokul of the Alliance and Ramlatu Attah, Sarah Fox and Tomas Lievens of OPM provided support in the review, data collection and analysis. M. A. Yushuf Sharker, statistician, ICDDR, B, provided support for the statistical analysis.

The contribution of the other members of the technical working group that oversaw and provided guidance to the development of the survey protocol is also gratefully acknowledged: Dr. Elsheikh Badr, Director of the National Human Resources for Health Observatory (NHRHO), Sudan; Professor Zulfiqar Bhutta, Division of Maternal and Child Health, The Aga Khan University, Pakistan; Dr. Eric Buch, Health Adviser, New Partnership for African Development Planning and Coordination Agency (NEPAD Agency) and Professor, Health Policy and Management, University of Pretoria, South Africa; Ms. Patralekha Chatterjee, independent journalist working for Indian and international media and public health analyst; Dr. Manuel Dayrit, Director, Department of Human Resources for Health, WHO, Switzerland; Mr. Bjarne Garden, Acting Director, Global Health and AIDS Department, Norwegian Agency for Development Cooperation (NORAD), Norway; Dr. Julian Schweitzer, Principal, Results for Development, United States of America; Dr. Julia Seyer, World Health Professions Alliance (WHPA) at the World Medical Association (WMA); Dr. Neil Squires, Senior Health Adviser, United Kingdom Department for International Development (DFID); and Ms. Marie-Odile Waty, Lead Health Specialist, International Finance Corporation, France.

\section{References}

[1] Travis P, Bennett S, Haines A et al. Overcoming health-systems constraints to achieve the Millennium Development Goals. Lancet. 2004; 364: 900-906. http://dx.doi.org/10.1016/S0140-6736(04)16987-0

[2] Anand S, Bärnighausen T. Human resources and health outcomes: cross-country econometric study. Lancet. 2004; 364, 1603-1609. http://dx.doi.org/10.1016/S0140-6736(04)17313-3

[3] Anand S, Bärnighausen T. Health workers and vaccination coverage in developing countries: an econometric analysis. Lancet. 2007; 369: 1277-1285. http://dx.doi.org/10.1016/S0140-6736(07)60599-6

[4] United Nations (UN). Access for all to skilled, motivated and supported health workers - Background paper to Global Strategy for Women's and Children's Health [Internet]. 2010. Available from: http://www.who.int/pmnch/activities/jointactionplan/20101007_4_skilledworkers.pdf.

[5] The Joint Learning Initiative. Overcoming the Crisis: Report of the Joint Learning Initiative. Cambridge: Harvard University Press. 2004.

[6] World Health Organization (WHO). World Health Report 2006: Working Together for Health. Geneva: WHO Press. 2006.

[7] Global Health Workforce Alliance (GHWA). The Kampala Declaration and Agenda for Global Action [Internet]. 2008. Available from: http://www.who.int/entity/workforcealliance/Kampala\%20Declaration\%20and\%20Agenda\%20web\%20file.\%20FINAL.pdf.

[8] Global Health Workforce Alliance (GHWA). Reviewing Progress, Renewing Commitment: Progress report on the Kampala Declaration and Agenda for Global Action [Internet]. 2011a. Available from: http://www.who.int/workforcealliance/forum/2011/progressreportlaunch/en/index.html.

[9] Van den Broek A, Gedik G, Poz MD et al. Human Resource for Health Observer 6: policies and practices of countries with a crisis in human resources for health. Geneva: WHO Press. 2010.

[10] Global Health Workforce Alliance (GHWA). Country Coordination and Facilitation (CCF): Principles and process [Internet]. 2010a. Available from: http://www.who.int/workforcealliance/countries/ccf/ccf/en/index.html.

[11] World Health Organization (WHO). Handbook on monitoring and evaluation of human resources for health: with special applications for low- and middle-income countries. Geneva: WHO Press. 2009.

[12] Lewin S, Munabi-Babigumira S, Glenton C et al. Lay health workers in primary and community health care for maternal and child health and the management of infectious diseases. Cochrane Database Syst Rev. 2010; 17: 3.

[13] Global Health Workforce Alliance (GHWA). Global Experience of Community Health Workers for Delivery of Health Related Millennium Development Goals - A Systematic Review, Country Case Studies, and Recommendations for Integration into 
National Health Systems [Internet]. 2010b. Available from:

http://www.who.int/workforcealliance/knowledge/themes/community/en/index.html.

[14] World Health Organization (WHO). Increasing access to health workers in remote and rural areas through improved retention. Geneva: WHO Press. 2010a.

[15] Dolea C, Stormont L, Braichet JM. Evaluated strategies to increase attraction and retention of health workers in remote and rural areas. Bull World Health Organ. 2010; 88: 379-385. PMid:20461133 http://dx.doi.org/10.2471/BLT.09.070607

[16] Organisation for Economic Co-operation and Development (OECD). International migration of health workers: improving international co-operation to address the global health workforce crisis. Paris: OECD. 2010.

[17] World Health Organization (WHO). Global Code of Practice on the International Recruitment of Health Personnel [Internet]. 2010b. Available from: http://who.int/hrh/migration/code/full_text/en.

[18] Stuckler D, Basu S, Gilmore A el al. An evaluation of the International Monetary Fund's claims about public health. Int J Health Serv. 2010; 40: 327-332. PMid:20440976 http://dx.doi.org/10.2190/HS.40.2.m

[19] Vujicic M, Ohiri K, Sparkes S. Working in health - financing and managing the public sector health workforce. Washington D.C.: World Bank. 2009. PMid:20095519

[20] Lu C, Schneider MT, Gubbins P et al. Public financing of health in developing countries: a cross-national systematic analysis. Lancet. 2010; 375 (9723): 1375-1387. http://dx.doi.org/10.1016/S0140-6736(10)60233-4

[21] Cometto G, Ooms G, Starrs A et al. A global fund for the health MDGs? Lancet. 2009; 373: 1500-1502. http://dx.doi.org/10.1016/S0140-6736(09)60835-7

[22] Dussault G, Dubois CA. Human resources for health policies: a critical component in health policies. Hum Resour Health. 2003; 1: 1. PMid:12904254 http://dx.doi.org/10.1186/1478-4491-1-1

[23] Sheikh M. Commitment and action to boost health workforce. Lancet. 2012; 379 (9810): 2-4. http://dx.doi.org/10.1016/S0140-6736(11)60023-8

[24] Global Health Workforce Alliance (GHWA). From Kampala to Bangkok: Reviewing Progress, Renewing Commitments Outcome Statement of the Second Global Forum on Human Resources for Health [Internet]. 2011b. Available from: http://www.who.int/workforcealliance/forum/2011/Outcomestatement.pdf. 